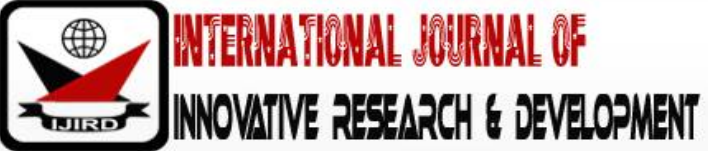

ISSN 2278 - 0211 (Online)

\section{Household Vulnerability to Climate Change among the Residents of Baringo County, Kenya}

\author{
Maurice Manyonge Pepela \\ Ph.D. Student, Department of Emergency Management Studies, \\ Masinde Muliro University of Science and Technology, Kenya \\ Dr. Edward Mugalavai \\ Lecturer, Department of Disaster Management and Sustainable Development, \\ Masinde Muliro University of Science and Technology, Kenya \\ Dr. Ferdinand Nabiswa \\ Lecturer, Department of Emergency Management Studies, \\ Masinde Muliro University of Science and Technology, Kenya
}

\begin{abstract}
:
Coping and adaptation to the impacts of climate change is increasingly necessary. Due to the expanding global climate change coping and adaptation agenda among various agencies, it is of primary importance to understand the coping and adaptation strategies in order to generate the most appropriate and effective interventions. The study evaluated the level of household vulnerability to climate change on the livelihoods of Baringo County based on Pressure and Release (PAR) model. The study assessed vulnerability to climate change at the household level. This study used statistical and econometric tools to establish or measure household vulnerability in Baringo County. It considered 26 socio-economic and biophysical indicators obtained from 204 households' in-depth interviews to reflect climate vulnerability components which include adaptive capacity, exposure and sensitivity. Principal component analysis (PCA) was used to develop weights for different indicators and produce a household vulnerability index (HVI) so as to classify households according to their level of vulnerability. On ordinal regression, $63.2 \%$ of the households showed high climate change vulnerability. On household vulnerability assessment, after assessing the Socio -Economic and Bio-Physical Vulnerability of the Household Heads, the study concludes that Baringo County is vulnerable to climate change. Majority of the household respondents were illiterate, lager families, female headed households and little access to extension services. In conclusion the government and other stakeholder should together work in collaboration to reduce household vulnerability especially in rural areas where it is rampant for this will be the genesis of addressing climate change.
\end{abstract}

Keywords: Household, vulnerability; climate change, livelihoods, coping, adaptation; disaster, mitigation

\section{Introduction}

This study carried out a local vulnerability assessment or measure to climate change in Baringo County. According to Posey (2009) most adaptive responses are made at the local level by resource managers, municipal planners, and individuals at the household level (household heads). As posted by Fazey et al. (2010) and Yoo et al. (2011) there has been relatively little attention given to how assessments can be conducted in ways that help build capacity for local communities to understand and find their own solutions to their problems. The study sought to address this empirical lacuna by conducting a household vulnerability assessment at the local community level with the focus $\mathrm{n}$ establishing household vulnerability among resident of Baringo County Kenya.

The evaluation of vulnerability considered the following characteristics the scale of vulnerability. These characteristics conveyed information on diverse natural environments and heterogeneous socio-economic structure at multiple scales which lacks in aggregate vulnerability indices. This was in line with Boyce (2003) who states that inequality aggravates environmental degradation, including climate change. The scale analysis of vulnerability took into account the bio-physical environmental difference of locations and the socio-economic contextual differences at the local level. Heterogeneity of locations even within a country or specific region is often responsible for differential response (i.e. coping capability) to that hazard (Adger, (1999); Carina \& Keskitalo, (2008) and Engle \& Lemos, (2010). Therefore, this study established the scale of vulnerability by looking at the heterogeneity of socio-economic contexts such as institutions, population, social network and culture, for this may affect the "local" vulnerability to climate change.

The vulnerability assessment also involved tools and processes used to assess the vulnerability of a community and its natural resources to climate change. The approach as suggested by (Marshall et al., 2010; USAID, 2009 and Turner 
et al., 2003) covered three main areas: exposure, sensitivity, and adaptive capacity, as they collectively determine the level of vulnerability to climate change impacts.

The vulnerability assessment looked at social vulnerability synonymously used with adaptive capacity, environmental vulnerability and also the interplay of both human and environmental vulnerability (Füssel \& Klein, 2006); Füssel, 2007). The aim was to enhance the understanding of factors that cause vulnerability in order to reduce associated risks (Adger et al., 2004).

Since there are an "almost infinite" number of indicators that may be used to measure vulnerability as stated by Hutchinson, (1992) and reinforced by Hinkel (2011), the study purposely identified the following indicators; sex, age, household size, education, marital status, extension services, early warning information, non - farm income, herd size, employment mobility, credit access among other indicators.

\section{Conceptual Framew ork}

This study was guided by Progression in Vulnerability as envisioned in the Pressure and Release Model (PAR model). This model gives disaster managers a framework for understanding vulnerability to disasters and for reducing it.

\subsection{Pressure and Release (PAR) Model}

This study was guided by Progression in Vulnerability as envisioned in the Pressure and Release Model (PAR model) as was advanced by Wisner et al. (2004). This model gives disaster managers a framework for understanding vulnerability to disasters and for mitigating disaster impact. The PAR model is a simple tool showing how disasters occur when natural hazards affect vulnerable people. The PAR Model only focuses on a disaster as an intersection of two opposing forces those generating vulnerability and the natural hazard. The model also conceptualizes the reduction of a disaster to relieve pressure by use of coping and adaptation strategies.

The basis for the PAR idea is that a disaster is the intersection of two opposing forces: those processes generating vulnerability on one side herein build around climate change and the natural disaster event (or sometimes a slowly unfolding natural process) on the other for example drought. The 'release' idea is incorporated to conceptualize the reduction of disaster: to relieve the pressure, vulnerability has to be reduced using coping and adaptation strategies.

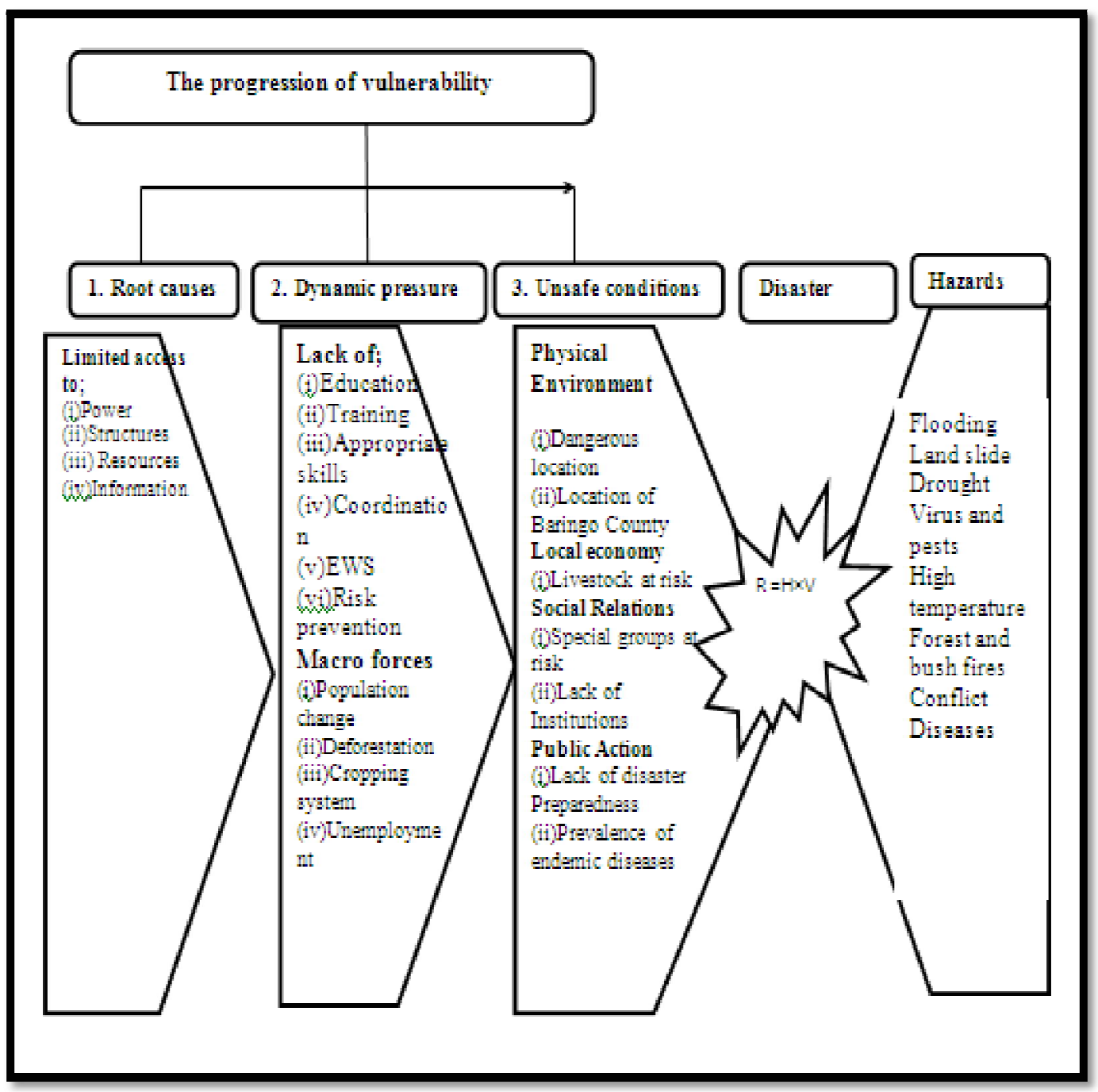

Figure 1: Pressure and Release (PAR) Model of Climatic

Disaster (Modified from Wisner Et Al., 2004) 


\section{Materials and Methods}

\subsection{Study Area}

Baringo County is one of the 47 Counties in Kenya. It is situated in the Rift Valley region. It borders Turkana and Samburu Counties to the north, Laikipia to the East, Nakuru and Kericho to the south, Uasin Gishu to the southwest, and Elgeyo-Marakwet and West Pokot to the west (BCG \& WFP, 2015). It is located between longitudes $35^{\circ} 30^{\mathrm{I}}$ and $36^{\circ} 30^{\mathrm{I}}$ east and between latitude $0^{0} 10^{\mathrm{I}}$ and $1^{0} 40^{\mathrm{I}}$ south. The Equator cuts across the County at the southern part. Baringo covers an area of 11,015.3 sq. km of which $165 \mathrm{sq} \mathrm{km}$ is covered by surface water; Lake Baringo, Lake Bogoria, and Lake Kamnarok (ADP 2017- 2018 Baringo, 2016). The research mainly covered three sub - counties of Baringo County and these were; Mogotio, Eldama Ravine and Baringo South. These three were purposively sampled because they exhibit the four livelihood zones of Baringo County and are region is vulnerable to climate change. The four livelihood zones are; mixed farming, pastoral, agro-pastoral and irrigated farming. Figure 2 shows the map of the three sampled Sub - Counties of Baringo County.

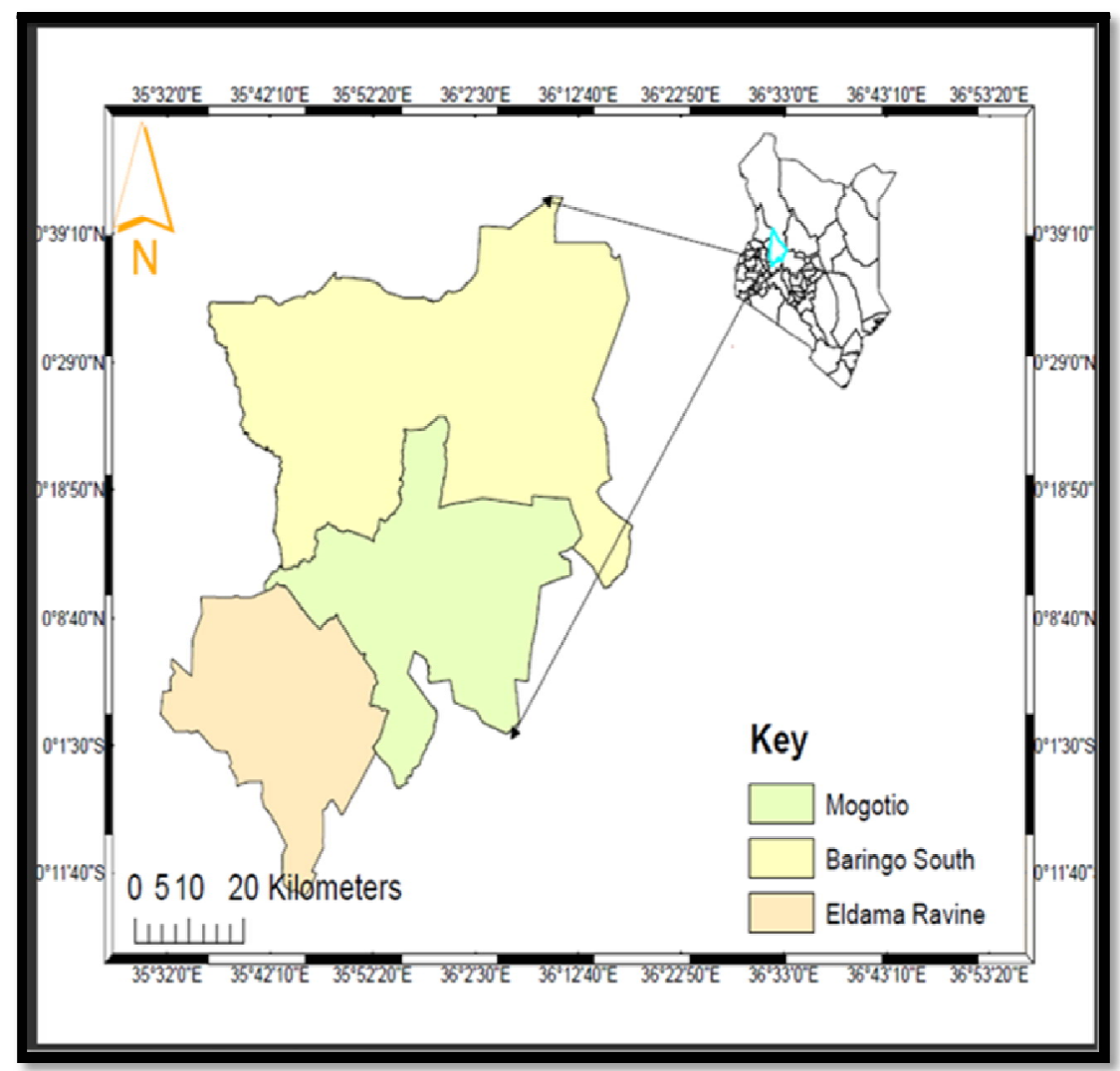

Figure 2: Map of Mogotio, Eldama Ravine and Baringo South sub - counties

\subsection{Research Design}

This study shall adopt evaluation research design. Evaluation research design is used to determine the impact of a social intervention. A social intervention is an action within a social context designed to produce an intended result. Evaluation research design having a very strong social validity was most appropriate for this study.

\subsection{Sampling Methods}

The sample size determination was as shown in Equation below. This is according to Nassiuma (2000) who asserts that in most surveys or experiments, a coefficient of variation in the range of $21 \%$ to $30 \%$ and a standard error in the range $2 \%$ to $5 \%$ is usually acceptable. Therefore, a coefficient of variation of $30 \%$ and a standard error of $2 \%$ was used. The higher limit for coefficient of variation and standard error was selected so as to ensure low variability in the sample and minimize the degree or error.

$$
S=\frac{N(C v)^{2}}{(C v)^{2}+(N-1) e^{2}}
$$

Where $\mathrm{S}=$ the sample size

$$
\begin{aligned}
& \mathrm{N}=\text { the population size } \\
& \mathrm{Cv}=\text { the Coefficient of Variation } \\
& \mathrm{e}=\text { standard error }
\end{aligned}
$$

Therefore, the sample size was determined using the formula:

$\mathrm{S}($ From73, $747 \mathrm{HHs})=\frac{73,747\left(0.30^{2}\right)}{0.3^{2}+(73747-1) 0.02^{2}}=222.73=223$ households 


\subsection{Data Collection}

The data collection methods for this research included both the quantitative and qualitative methods. In qualitative data collection, observations and field notes were chronologically recorded to draw a single conclusion. The qualitative data collection methods that were used in this research included; questionnaires, observation, in-depth interviews, key informant schedules and focus group discussions. Since each method is particularly suited for obtaining a specific type of primary data. During data collection 204 questionnaires were completed and returned out of 223 questionnaires. The deficit was addressed through the focus group discussions and the interview schedules making the data reliable.

\subsection{Data Analysis}

The analysis was performed using ordinal logistic regression analysis. The ordinal logit model is used when the outcome variable is categorized in an ordinal scale, as in this case where vulnerability is ordered as (1) highly vulnerable, which implies households for whom the difference between adaptive capacity and sensitivity/ exposure is significantly negative; (2) moderately vulnerable, which means that households for whom the difference between adaptive capacity and sensitivity/ exposure is nearly zero; and (3) less vulnerable, which means that the difference between adaptive capacity and exposure/ sensitivity is significantly positive.

\section{Results and Discussions}

\subsection{Hazards Reported by Households in Baringo County}

The study sought to know the intensity or severity of listed type of hazards as felt or perceived at the household level in Baringo County and the severity. The household heads were asked rank the identified hazards they have faced in the area for the past 30 years based on the severity or their intensity. The results were as indicated in Table 1.

\begin{tabular}{|c|c|c|c|c|c|}
\hline Hazard & Intensity/ severity & $\begin{array}{l}(\mathrm{N}= \\
204)\end{array}$ & Percentage & $\chi^{2}$ & $P$ - value \\
\hline \multirow[t]{5}{*}{ Drought } & & & & \multirow[t]{5}{*}{260.039} & \multirow[t]{5}{*}{$0.000^{* * *}$} \\
\hline & Very severe & 150 & 73.5 & & \\
\hline & Moderately severe & 29 & 14.2 & & \\
\hline & Less severe & 15 & 7.4 & & \\
\hline & Not sure & 10 & 4.9 & & \\
\hline \multirow[t]{5}{*}{ Floods } & & & & \multirow[t]{5}{*}{16.706} & \multirow[t]{5}{*}{0.001} \\
\hline & Very severe & 68 & 33.3 & & \\
\hline & Moderately severe & 62 & 30.4 & & \\
\hline & Less severe & 42 & 20.6 & & \\
\hline & Not sure & 32 & 15.7 & & \\
\hline \multirow[t]{5}{*}{ Livestock diseases } & & & & \multirow[t]{5}{*}{34.627} & \multirow[t]{5}{*}{$0.000^{* * *}$} \\
\hline & Increasing & 82 & 40.2 & & \\
\hline & Decreasing & 26 & 12.7 & & \\
\hline & Constant & 57 & 27.9 & & \\
\hline & Not sure & 39 & 19.1 & & \\
\hline \multirow{5}{*}{$\begin{array}{l}\text { Vectors (human and } \\
\text { animals) }\end{array}$} & & & & \multirow[t]{5}{*}{80.392} & \multirow[t]{5}{*}{$0.000^{* * *}$} \\
\hline & Increasing & 100 & 49.0 & & \\
\hline & Decreasing & 12 & 5.9 & & \\
\hline & Constant & 38 & 18.6 & & \\
\hline & Not sure & 54 & 26.5 & & \\
\hline \multirow[t]{5}{*}{ Human diseases } & & & & \multirow[t]{5}{*}{55.333} & \multirow{5}{*}{$0.000^{* * *}$} \\
\hline & Increasing & 95 & 46.6 & & \\
\hline & Decreasing & 24 & 11.8 & & \\
\hline & Constant & 40 & 19.6 & & \\
\hline & Not sure & 45 & 22.1 & & \\
\hline \multirow[t]{5}{*}{ Resource based conflict } & & & & \multirow[t]{5}{*}{73.686} & \multirow[t]{5}{*}{$0.000 * * *$} \\
\hline & Increasing & 104 & 51.0 & & \\
\hline & Decreasing & 31 & 15.2 & & \\
\hline & Constant & 33 & 16.2 & & \\
\hline & Not sure & 36 & 17.6 & & \\
\hline
\end{tabular}

Table 1: Hazards Identified by the Respondents at the Household Level (Field Data, 2018)

The results in Table 1 show that majority 150(73.5\%) of the households indicated that drought they had experienced for the past 30 years was very severe, 29(14.2\%) indicated moderately severe 15(7.4\%) less severe while $10(4.9 \%)$ indicated that they were not sure. A calculated chi - square of $260.039, \mathrm{P}$-value $=0.000 * * *$ and $\mathrm{df}=3$ revealed that 
the responses were highly significant. The findings also revealed that majority $68(33.3 \%)$ of the household respondents indicated that they had been very severely affected by floods in the past 30 years, 62(30.4\%) moderately severely affected, $42(20.6 \%)$ less severely while $32(15.7 \%)$ where not sure. A calculated chi - square of $16.706, \mathrm{P}$-value $=0.001$ and $\mathrm{df}=3$ revealed that the responses were highly significant.

Further, the findings in Table 1 indicates that majority 82(40.2\%) of the household respondents noted an increase in livestock diseases in the past 30 years, 26(12.7\%) noted a decrease, 57(27.9\%) indicated constant while 39(19.1\%) were not sure in the changes of livestock diseases. A calculated chi - square of 34.627, P-value $=0.000 * * *$ and $\mathrm{df}=3$ revealed that the responses were highly significant. On human and animal vectors, the findings recorded in Table 1 shows that majority 100(49.0\%) of the household respondents indicated that there had been an increase in human and animal vectors for the past 30 years, $12(5.9 \%)$ indicated decrease, 38(18.6\%) indicated constant while $54(26.5 \%)$ were not sure of the changes in the human and animal vectors in the past 30 years A calculated chi - square of 80.392 , P-value $=0.000 * * *$ and $\mathrm{df}=3$ revealed that the responses were highly significant.

In addition, Table 1 shows that majority 95(46.6\%) of the household heads indicated that in the past 30 years they had been an increase in human diseases, 24(11.8\%) indicated there was a decrease, 40(19.6\%) indicated constant while 45(22.1\%) indicated that they were not sure with the changes in the human diseases for the past 30 years. A calculated chi - square of 55.333, P-value $=0.000^{* * *}$ and $\mathrm{df}=3$ revealed that the responses were highly significant. The findings in Table 1 also revealed that majority 104(51.0\%) of the household respondents cited resource based conflict as a hazard that have affected the community for the past 30 years and had been on increase, 31(15.2\%) indicated a decrease in the conflicts, $33(16.2 \%)$ indicated that there was no change resources based conflicts while 36(17.6\%) of the household respondents indicated that they were not sure. A calculated chi - square of 73.686, P-value $=0.000^{* * *}$ and $\mathrm{df}=3$ revealed that the responses were highly significant.

These findings were corroborated with the interview schedules with all the key informants who were all in agreement in terms of the severity and severity of the various hazards in Baringo County. The findings in Table 1 was in agreement with majority of the focus group discussants who informed the study that drought and floods have been on increase in severity and intensity in the past 30 years. On human, livestock diseases and vectors, the focus group discussants were all in agreement that they had been an increase. For the case of resource-based conflicts all the focus group discussants were in agreement that they had been on increase which had been as a result of perennial drought and floods. This finding corroborates with Patz et al. (2005) that asserted that the major impacts of climate change include severe floods, frequent and prolonged droughts, crop failure, loss of livestock, lower water availability and quality and an increase in vector and water-borne diseases. This is also in agreement with Ebi et al. (2007) that indicated that climate change-related impacts on the ecosystems are likely to affect population by creating favourable conditions for disease vectors or disease pathogens as well as placing the communities at high risk of malnutrition, diarrheal diseases and other environmental health effects attributable to climate change.

The findings in Table 1 corroborates with secondary data in Table 2 from the Office of the Deputy Governor Baringo County in the Department of Disaster Management.

\begin{tabular}{|c|c|}
\hline Hazard* & Rank \\
\hline Drought & 1 \\
\hline Conflict & 2 \\
\hline Human Diseases & 3 \\
\hline Livestock Diseases & 4 \\
\hline Crop Diseases & 5 \\
\hline Floods & 6 \\
\hline Wild Fires & 7 \\
\hline Land Degradation & 8 \\
\hline Fires & 9 \\
\hline Accidents & 10 \\
\hline Land Slides & 11 \\
\hline
\end{tabular}

Table 2: Hazards Manifested In the County Ranked Based on the Magnitude of Exposure

Disaster Management Office Baringo County, 2018

Table 2 indicates that Drought is ranked as the County's leading hazard exposure in terms of magnitude and spread. Drought is also regarded as one of the most important players in shaping the socioeconomic structure and livelihood system in Baringo. According to the County's disaster risk platform (CDRR) recent increase in the frequency of droughts has been linked to climate change trends in the County majorly as a result of routine delays and unpredictability of the long rains season (NDMA, 2016). Adverse societal factors such as poor land-use practices, conflicts, poverty, poor communication infrastructure and lack of (or poorly implemented) traditional coping mechanisms are also major catalysts of drought disasters in the County (NDMA, 2016).

Drought events were reported to be frequent hazards in the area and had devastating impacts on household livelihoods, pasture and water, which escalates the area's chronic conflicts, insecurity and food insecurity. This was echoed by the respondents during the focus group discussion; the study was informed that resource - based conflict has regularly 
led to loss of life and livelihoods undermining human and livestock population mobility, as well as development efforts. One of the respondents informed the study that there was a year he lost his entire livelihood due to the conflicts;

This thing is bad, there is a year I lost all my wealth, cattle and goats all died). (Field Data, 2018) NDMA (2016) has noted that the most commonly occurring types of drought in Baringo County are meteorological, agricultural and hydrological drought. These are classified according to their causes and manifestation in the county. According to UNDP (2012) Meteorological Drought is common in the low-lying regions of Baringo County including Marigat (Baringo South Sub - County), Mogotio and parts of East Pokot. Baringo County Government (2014) indicates that a major drought also occurred in the County during the period 2008-2011.

\subsection{Floods Occurrence}

Table 1 indicates that flooding was identified second priority hazard while in Table 2 is rated as $6^{\text {th }}$. However, according NDMA (2016) floods over recent years have become more routine regularly causing disasters, which lead to emergency operations, particularly along both permanent and seasonal rivers in the County and in areas surrounding major lakes mainly lake Baringo and to some extent lake Bogoria. During the interview schedule with Director Disaster Management Baringo County ranked Baringo South sub-county as the most at risk and impacted by flooding followed by Mogotio and East Pokot sub - counties respectively.

The Flood Assessment Report of August 2013 by NDMA reported about 5 cattle, 63 goats, 12 dogs and 134 chickens were lost during the floods. According to Irinnews.org (2012) mudslides caused by the heavy rains of April 2015 killed two children, ages 12 and 15, and injured seven other people. Figure 3 shows one of the household's heads explaining how flooding destroyed his farm in Baringo South Sub - County.

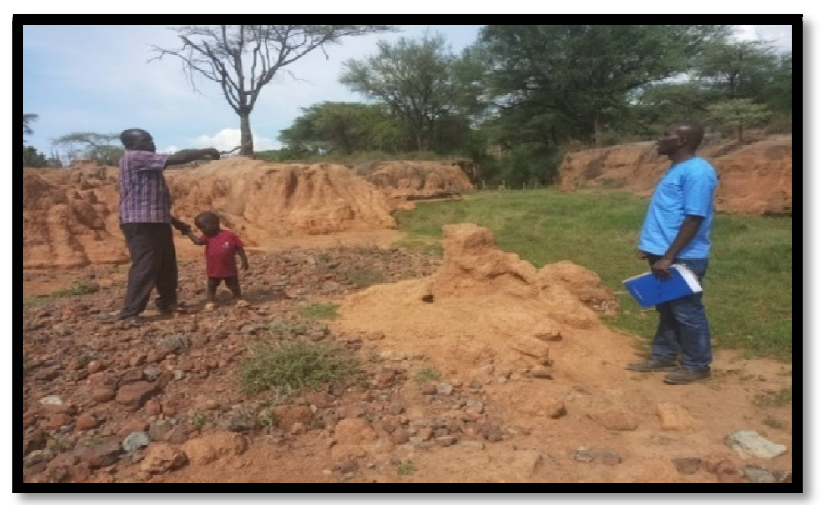

Figure 3: One of the Household Heads Showing How Flooding Destroyed His Farm in Baringo South Sub - County, Kenya (Field Data, 2018)

Figure 4 indicates an approximate number affected population by flooding in Baringo County by 2013.

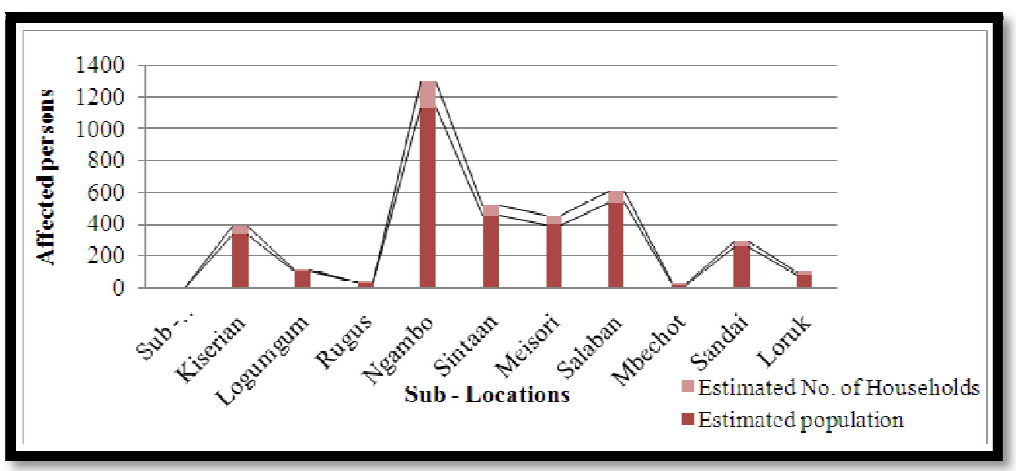

Figure 4: Approximate Affected Population (Flood Assessment Report of August 2013 by NDMA)

NDMA (2013) indicated that the rains in August 2013 affected about 1764 ha of cropland and 61740 of pasture and browse land in Baringo. According to Floodlist.com (2013) Heavy rains in the year 2013 increased water levels of Lake Baringo in western Kenya, forcing around 2,000 people in Marigat district to flee their homes for higher ground. Calamitous flooding in Baringo caused by heavy rains like that of April 2015 led to cut off of three health centres, several tourist lodges and 10 schools (TRUST, 2016).

\subsection{Livestock, Crop and Human Diseases}

The respondents were further asked to indicated the intensity and severity of livestock, crop and human diseases and their responses are captured in Table 1 which shows that human diseases 100(49.0\%) and livestock diseases $82(40.2 \%)$ have been on the rise and were ranked $3^{\text {rd }}$ and $4^{\text {th }}$ respectively by the Disaster Management Office Baringo County as indicated in Table 2. On further interrogation, the households' respondents identified the outbreak of 
mosquitoes locally referred to as kipichan that has led to an increase in malaria (esee) in the past two decades. In addition, study established that there is an increase in effects of sandflies that has been the cause of a disease called Kalaazar. During the focus group discussion, the respondents informed the study that the increase in sandflies has been due to increase in the number of dormant anthills that form breeding places, cracks in muddy houses (Figure 5) and also tree holes have been a safe haven for the sandflies. The study was further informed that since most of the houses are made of mud with many cracks, this has made many households vulnerable to kalaazar. This was also echoed by key informants during the interview schedules. Other diseases that respondents identified to be on increase included typhoid (romopkee), pneumonia (koroita tegee), brucellosis (koroita chegoo) and amoebic dysentery (romopkee).

According to NDMA (2016), flooded areas have led to increase in water borne diseases such as cholera and vector borne diseases such as malaria. This is because the flood waters contribute to the creation of a habitat where vectors such as mosquitoes lay eggs and multiply.

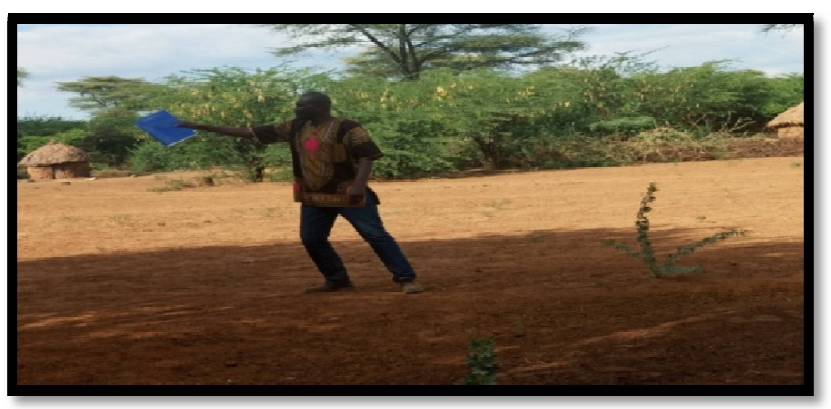

Figure 5: Showing Muddy House in Baringo County That Exposes Residents to Sandflies

4.4. Socio - Economic and Bio-Physical Vulnerability of the Household Heads

The study sought to establish the socio - economic and bio - physical vulnerability of the household heads. The social and economic variables contributing to vulnerability were captured in Table 3.

\begin{tabular}{|c|c|c|}
\hline Variable & Percentage & Influence on Vulnerability a \\
\hline \multicolumn{3}{|l|}{ Social Vulnerability Variable } \\
\hline Sex of HH head: female headed & 56.4 & + \\
\hline Age of HH head: 50+years & 47.2 & - \\
\hline HH size: More than 5 members & 70.4 & - \\
\hline Education level: primary education and below & 88.7 & + \\
\hline Marital status: Single & 38.2 & - \\
\hline Extension services: no access & 30.4 & + \\
\hline Early warning information: no access & 52.5 & + \\
\hline \multicolumn{3}{|l|}{ Economic vulnerability variable } \\
\hline Non-farm income: no non-farm income & 32.4 & - \\
\hline Herd size: own less than 2 TLU & 20.4 & + \\
\hline Property regime: Own property land & 9.4 & - \\
\hline Distance to market: more than $10 \mathrm{~km}$ away & 40.3 & - \\
\hline Access to remittances: no cash transfers & 64.2 & + \\
\hline HH employed: no member of $\mathrm{HH}$ employed & 89.4 & + \\
\hline HH coping strategies: $>2$ coping strategies & 83.0 & + \\
\hline Livestock diversity: <2 livestock species & 47.0 & - \\
\hline Credit Access: no access to credit at all & 75.4 & + \\
\hline Mobility: Able to move livestock freely & 46.4 & \\
\hline
\end{tabular}

Table 3: Social and Economic Indicators and Their Effect on Vulnerability Level

Apositive Sign Indicates That the Variable Increases Vulnerability,

While Bnegative Sign Means It Reduces Vulnerability

TLU; Total Livestock Unit, $\mathrm{HH}$; Household

(Field Data, 2018)

The social and economic variables are summarized in Table 3. The finding shows that more $80 \%$ of the household respondents had no secondary education and the majority is unable to read and write. This in turn reduces a household's ability to understand climatic information, access market and early warning information hence increasing climate change vulnerability hence influence on vulnerability is positive (+). Data on the household size showed that $70.4 \%$ of the sampled household had more than 5 members. The more numbers of members in a household reduces vulnerability since it's believed that the more the household members the more sources of income. This will automatically reduce vulnerability, hence influence on vulnerability is negative (-). The sex of the household head which is critical to climatic adaptation and coping revealed that more than $50 \%$ of the households were female headed, hence the influence on vulnerability positive 
(+). In addition, more than $30.4 \%$ of the respondents indicated that they do not have access to extension services and this has a positive (+) influence on vulnerability. Further findings show that $38.2 \%$ of the households were single and this had negative (-) influence on vulnerability. The results imply that the vulnerability level of households to the frequently occurring climate-induced stresses is largely determined by gender and education level of the household head in the study area.

The results also indicate that $89.4 \%$ of the households had none of the family member formally employed and 83.0\% use more than 2 coping strategies to survive in the harsh climatic conditions. This also has made households vulnerable to effects of climate changes since they are more exposed and lack cushion in the event of drought or flooding. The study also sought to establish environmental vulnerability of the respondents. The findings were as shown in Table 5.

\begin{tabular}{|c|c|c|}
\hline Variable & percentage & Influence on Vulnerability \\
\hline Environmental vulnerability variable & & \\
\hline Climate change: experiencing change & 86.1 & + \\
\hline Flood: noticed change & 39.9 & + \\
\hline Temperature: experiencing increase & 50.5 & + \\
\hline Drought: noticed increasing events & 58.8 & + \\
\hline HH facing more than 2 hazards in 5 years & 70.9 & - \\
\hline
\end{tabular}

Table 4: Environmental Indicators and Their Effect on Vulnerability Level Apositive Sign Indicates That the Variable Increases Vulnerability, While ${ }^{B}$ negative

Sign Means It Reduces Vulnerability (Field Data, 2018)

Table 4 displays environmental indicators for climate induced climate change. 86.1\% of the respondents informed the study that they had experienced climate change, 39.9\% noticed a change in flooding and have been affected by floods, $50.5 \%$ of the household respondents said to be experiencing increase in temperature. In addition, $58.8 \%$ of the respondents said to have noticed an increase in drought events in Baringo County while $70.9 \%$ informed the study that they have faced more than 2 hazards in the past 5 years whereby this have contributed negatively to the vulnerability level of households.

\subsection{Measuring Household Level Vulnerability In Baringo County}

The study did a further analysis to measure household level vulnerability in Baringo County. Table 5 highlights the result of principal component analysis and its association with the social, economic and environmental variables. The factor scores (weights) of the first principle component analysis was positively associated with the majority of the indicators identified under adaptive capacity, exposure and sensitivity.

\begin{tabular}{|l|l|l|l|l|}
\hline & \multicolumn{3}{|c|}{ Component } \\
\hline Factors & & & $\mathbf{1}$ & \\
\hline Social Vulnerability Variable & & & & \\
\hline Sex of HH head: female headed & & & .380 & \\
\hline Age of HH head: 50+years & & -.001 & \\
\hline Education level: primary education and below & & -.166 & \\
\hline Marital status: Single & & -.127 & \\
\hline HH size: More than 5 members & & -.034 & \\
\hline Extension services: no access & & & -.258 & \\
\hline Early warning information: no access & & .255 & \\
\hline Economic vulnerability variable & & & & \\
\hline Non-farm income: no non-farm income & & & -.704 & \\
\hline Herd size: own less than 2 TLU & & -.553 & \\
\hline Property regime: Own property land & & .441 & \\
\hline Distance to market: more than 10km away & & & -.019 & \\
\hline Access to remittances: no cash transfers & & -.065 & \\
\hline HH employed: no member of HH employed & & & -.333 & \\
\hline HH coping strategies: $>$ 2 coping strategies & & & -.411 & \\
\hline Livestock diversity: <2 livestock species & & & -.258 & \\
\hline Credit Access: no access to credit at all & & & -.349 & \\
\hline Mobility: able to move livestock freely & & & .211 & \\
\hline
\end{tabular}

Table 5: Factor Score for the Principal Component Analysis for Social and Economic Variables

Extraction Method: Principal Component Analysis.

A. 4 Components Extracted.

(Field Data, (2018) 
Holding exposure and sensitivity constant, a negative index shows that the household had a relatively lower adaptive capacity when compared to a household with a positive index value and vice versa.

\begin{tabular}{|c|c|c|}
\hline & Component & \\
\hline & & 1 \\
\hline Climate change: experiencing change & & -.010 \\
\hline Flood: noticed change & & -.200 \\
\hline Temperature: experiencing increase & & -.491 \\
\hline Drought: noticed increasing events & & -.760 \\
\hline HH facing more than 2 hazards in 30 years & & -.333 \\
\hline $\begin{array}{c}\text { Extraction Method: Principal Component Analysis. } \\
\text { a. } 4 \text { components extracted. } \\
\text { (Field Data, 2018) }\end{array}$ & & \\
\hline
\end{tabular}

Table 6: Factor Score for the First Principal Component Analysis of Environmental Variables

The results in Table 6, the factor score for the first principal component analysis of environmental variables indicate that the component factor for experiencing climate change is -0.10 , noticed change in floods was - 0.200 , experiencing increase in Temperature was -0.491 , noticed drought increasing events was -0.760 while households facing more than two hazards in 30 years was -0.333 . The factor score indicates that climate change is evident in Baringo County and majority of the households of the households experience the effects of climate change.

\subsection{Vulnerability Levels at the Household Level in Baringo County}

The study sought to establish the level of vulnerability at the household level. The study population was put in three categories; 1. High Vulnerability, 2. Moderate vulnerability and 3. Low vulnerability. Table 7 shows the findings from the 204 households of Baringo South, Mogotio and Eldama Ravine in Baringo County.

\begin{tabular}{|c|c|c|c|}
\hline & N & Marginal Percentage \\
\hline \multirow{3}{*}{$\begin{array}{c}\text { Levels of Vulnerability } \\
\text { at household levels }\end{array}$} & High Vulnerability & 129 & $63.2 \%$ \\
\cline { 2 - 4 } & $\begin{array}{c}\text { Moderate } \\
\text { Vulnerability }\end{array}$ & 35 & $17.2 \%$ \\
\cline { 2 - 4 } & Low Vulnerability & 40 & $19.6 \%$ \\
\hline \multicolumn{2}{|c|}{ Total } & 204 & $100.0 \%$ \\
\hline
\end{tabular}

Table 7: The Level of Vulnerability at the Household Levels in Baringo County Aordinal Regression (Field Data, 2018)

The findings show that 129 (63.2\%) of the households are of high vulnerability, 35 (17.2\%) are of moderate vulnerability while 40 (19.6\%) are of low vulnerability. Chi-square of 82.265 with 2 - degree of Freedom and a p-value of $0.000^{* * *}$ tells us that vulnerability as a whole is statistically significant.

\section{Conclusions and Recommendation}

\subsection{Conclusion}

On household vulnerability assessment, after assessing the Socio -Economic and Bio-Physical Vulnerability of the Household Heads, the study concluded that Baringo County is vulnerable to climate change. Majority of the household respondents were illiterate, lager families, female headed households and little access to extension services. The results imply that the vulnerability level of households to the frequently occurring climate-induced stresses is very high in the study area. Based on the principal component analysis and its association with the social, economic and environmental variables the study revealed that the level of household vulnerability was high.

\subsection{Recommendation}

Climate change vulnerability can be reduced by addressing the social and economic indicators that have an effect on vulnerability. This can be done effectively by increasing extension services to farmers, improving the education standards of the residents, marking available the early warning information, and availing credit services. Stakeholder should together work in collaboration to reduce household vulnerability especially in rural areas where it is rampant for this will be the genesis of addressing the effects of climate change

\section{References}

i. Adger, W. Neil (1999). "Social vulnerability to climate change and extremes in coastal Vietnam". In: World Development 27.2, pp. 249-269. 
ii. Adger, W. N., Brooks, N., Bentham, G., Anew, M., \& Eriksen, S. (2004). New indicators of vulnerability and adaptive capacity. In T. C. f. C. C. Research (Ed.), (Vol. 122). Norwich, UK.

iii. Baringo County Government (2014). Baringo Drought Contingency Plan.

iv. Baringo County Government and World Food Programme (2015). Baringo County Capacity Gaps and Needs Assessment. Nairobi. World Food Programme.

v. Baringo County Annual Development Plan 2017 - 2018 (2016). County Treasury and Economic Planning, August 2016.

vi. Boyce, C., \& Neale, P. (2006). Conducting in-Depth Interviews: A Guide for Designing and Conducting in-Depth Interviews for Evaluation input. in P. International (Ed.), Pathfinder International Tool Series (Pp. 1-16).

vii. Carina, E. \& Keskitalo H, (2008). "Vulnerability and adaptive capacity in forestry in northern Europe: a Swedish case study," Climatic Change 87(1-2):

viii. Ebi, K., Woodruff, R., Hildebrand, A. \& Corvalan, C. (2007) Climate change related health impacts in the Hindu Kush-Himalayas. EcoHealth 4, no. 3: 264 - 270.

ix. Engle, N.L. \& Lemos M.C., (2010). Unpacking governance: Building adaptive capacity to climate change of river basins in Brazil," Global Environmental Change 20(1)

x. Fazey, I., Kesby, Evely M. A., Latham I., Wagatora D, Hagasua, J., Reed M.S., Christie M., (2010). A three-tiered approach to participatory vulnerability assessment in the Solomon Islands. Global Environmental Change 20(4)

xi. Floodlist.com (2013). Floods in Kenya. Copernicus Europe's eyes on Earth. Accessed August 2017

xii. Füssel, H.-M. (2007). Vulnerability: a generally applicable conceptual framework for climate change research. Global environmental change, 17, 155-167.

xiii. Füssel, H.-M., \& Klein, R. J. (2006). Climate change vulnerability assessments: an evolution of conceptual thinking. Climatic Change, 75(3).

xiv. Hinkel,J. (2011). Indicators of vulnerability and adaptive capacity: towards a clarification of the science-policy interface. Global Environmental Change 21

xv. Hutchinson, C. F. (1992). Early Warning and Vulnerability Assessment for Famine Mitigation. Washington, DC: USAID/ OFDAhttp:// www irinnews.org Environment and Disasters 2012.

xvi. Marshall, N. A., Marshall, P. A., Tamelander, J., Obura, D., Malleret-King, D., \& Cinner, J. E. (2010). A framework for social adaptation to climate change. Gland, Switzerland: IUCN (International Union for Conservation of Nature).

xvii. National Drought Management Authority (NDMA) (2016). Baringo County Hazard Atlas.http:/ / www.rcmrd.org

xviii. Patz, J.A., Campbell-Lendrum, D., Holloway, T. \& Folley, J.A. (2005) Impact of regional climate change on human health. Nature 438, 310-317.

xix. Posey, J. (2009). "The determinants of vulnerability and adaptive capacity at the Municipal level: Evidence from floodplain management programs in the United States," Global Environmental Change 19(4)

xx. Turner B.L., Kasperson R.E., Matson P.A., McCarthy J.J., Corell R.W., Christensen L., Eckley N., Kasperson J.X., Luers A., Martello M.L., Polsky C., Pulsipher A., and Schiller A. (2003). A Framework for Vulnerability Analysis in Sustainability Science. Proceedings of the National Academy of Sciences. http:/ / yaquivalley.stanford.edu/pdf/ turner_matson_2003.pdf

xxi. UNDP (2012).Africa Development Report 2012: Towards a Food Secure Future. Yoo, G., J.H. Hwang, C. Choi, (2011). "Development and application of a methodology. For vulnerability assessment of climate change in coastal cities," Ocean and Coastal Management 54(7)

xxii. Wisner B, Blaikie P, Cannon T, Davis I, (2004) At Risk: Natural Hazards, People's Vulnerability and Disasters (Routledge, London) 